\title{
Simulation Study of Electro spark Deposition on Die Steel
}

\author{
He Huang, Cunping Liu \& Sheng Guo \\ Department of Modern manufacturing, Yibin Vocational and Technical College, Yibin 644003, China
}

\begin{abstract}
The electro spark deposition (ESD) is an ideal process tor material increase manufacturing in many industrial sectors. In this paper, simulation of electro spark deposition and thermal analysis for this technology on $\mathrm{Cr} 12 \mathrm{MoV}$ steel is presented with the finite element software. Material deposition is analyzed using a thermo numerical model, which simulated the single spark operation. The suitable discharge conditions for the electro spark deposition was predicted through finite element method analysis. The results showed that the thermal action of the electro spark deposition affected the surface of deposited workpiece.
\end{abstract}

KEYWORD: Die Steel; ESD; Deposition

\section{INTRODUCTION}

Electro spark deposition (ESD) is a coating process, which short duration, high current electrical pulses are supplied between the electrode and the workpiece. A coating is deposited onto the surface of workpiece by pulse arc micro welding. This technique has been used to enhance the performance of electrical contact points[1] and increase service life of many parts subjected to wear, such as tools, drills, milling cutters, turbine blades and so on[1-3].

ESD is capable of creating complex threedimensional shapes and it has gained in popularity for the micro manufacturing because of its low setup costs, high accuracy and large design freedom. The fact that ESD machine is a non-contact process makes high precision machine on curved surfaces, inclined surfaces and even very thin sheet materials. In spite of the increasing popularity of this technique, for the ESD to be inefficient in industry, it needs to combine a high rate of material deposition and excellent surface quality. The process parameters of ESD are still in the developmental stage. A number of researchers have shown that an effective method for the evaluation of the conventional ESD process is through thermal models that an effective method for the evaluation of the conventional ESD process is through thermal models that predict the amount of material deposition during a single pulse. These studies are developed for the conventional ESD process. Numerical studies focusing on the influence of process parameters have been reported for understanding the ESD process [4-5].
In this study, a process simulation for the ESD process on $\mathrm{Cr} 12 \mathrm{MoV}$ steel will be presented. Material YG8 deposition will be analyzed using ANSYSbased thermo-numerical model for a single spark discharge process.

\section{ANSYS-BASED THERMAL MODELING OF THE ESD PROCESS}

For the transient, non-linear thermal simulation, we consider a single spark cycle which includes a spark on-time of $2 \mu \mathrm{s}$ and a spark off-time of $200 \mu \mathrm{s}$. Thermal diffusion equation for the heat transfers of the workpiece is following [6].

$p c \frac{\partial \mathrm{T}}{\partial t}=\frac{1}{r} \frac{\partial}{\partial}\left(\mathrm{k} \frac{\partial \mathrm{T}}{\partial \mathrm{r}}\right)+\frac{\partial}{\partial z}\left(\mathrm{k} \frac{\partial \mathrm{T}}{\partial \mathrm{y}}\right)$

Where $P$ is the density, $c$ is the specific heat capacity. $\mathrm{T}$ is the temperature, $\mathrm{t}$ is the time, $\mathrm{k}$ is thermal conductivity, and $\mathrm{r}$ and $\mathrm{y}$ is the coordinates of cylindrical work domain.

A schematic diagram of the thermal model with the applied boundary conditions is showed in fig.1. On the top surface the heat transferred to the workpiece is represented by a Gaussian heat flux distribution during the spark time. Coolant and ambient air is modeled using convective boundary conditions on surfaces 1 and 3 . No heat transfer occurs across surfaces 2 or 4 as they are either symmetry line or boundary in the far distance. Where $\mathrm{q}(\mathrm{r})$ is the heat flux entering the workpiece during the on-time and it has a zero magnitude during the off-time. 


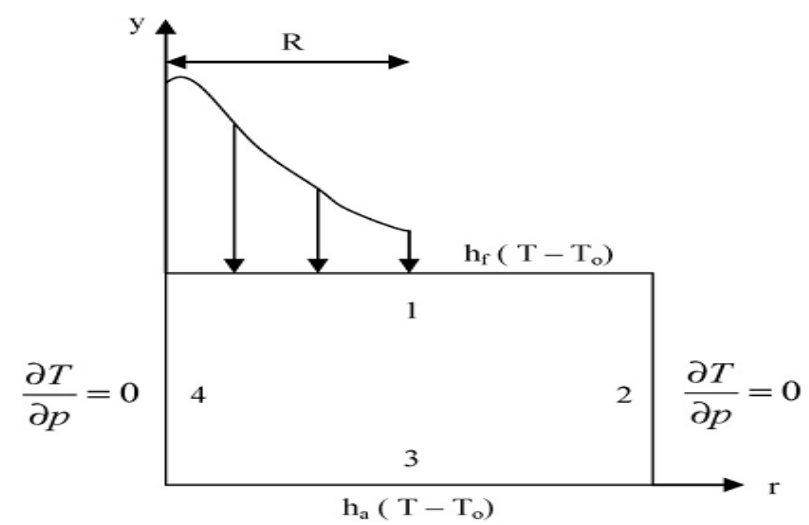

Fig. 1 An axisymmetric model for the EDM process simulation

A Gaussian heat flux distribution is assumed as follows in this study [7].

$\mathrm{q}(\mathrm{r})=\mathrm{q}_{\mathrm{m}} \exp \left\{-\mathrm{kr}^{2}\right\}$

Where $q(r)$ is the surface heat flux density at the position of radius $r$ and depends on discharge pa- rameters; qm is the maximum heat flux density; $\mathrm{k}$ is the heat concentration factor.

\section{SIMULATION RESULTS AND DISCUSSION}

\subsection{Temperature field simulation.}

The temperature distribution simulation was analyzed in the finite element software ANSYS. Fig.2 and Fig. 3 showed the temperature field distribution of the deposition materials and workpiece. By comparing Fig.2(a) with Fig.(a), the iso-surface of workpiece is relatively denser than deposition materials, and the heat affected zone of deposition is larger than workpiece. Through the analysis of the start discharge process(Fig.2(b) and Fig.3(b)), it is found that the high temperature mainly ranges between discharge central point and $0.002 \mathrm{~m}$. Certainly, specific heat capacity has remarkable effect on the discharge process.
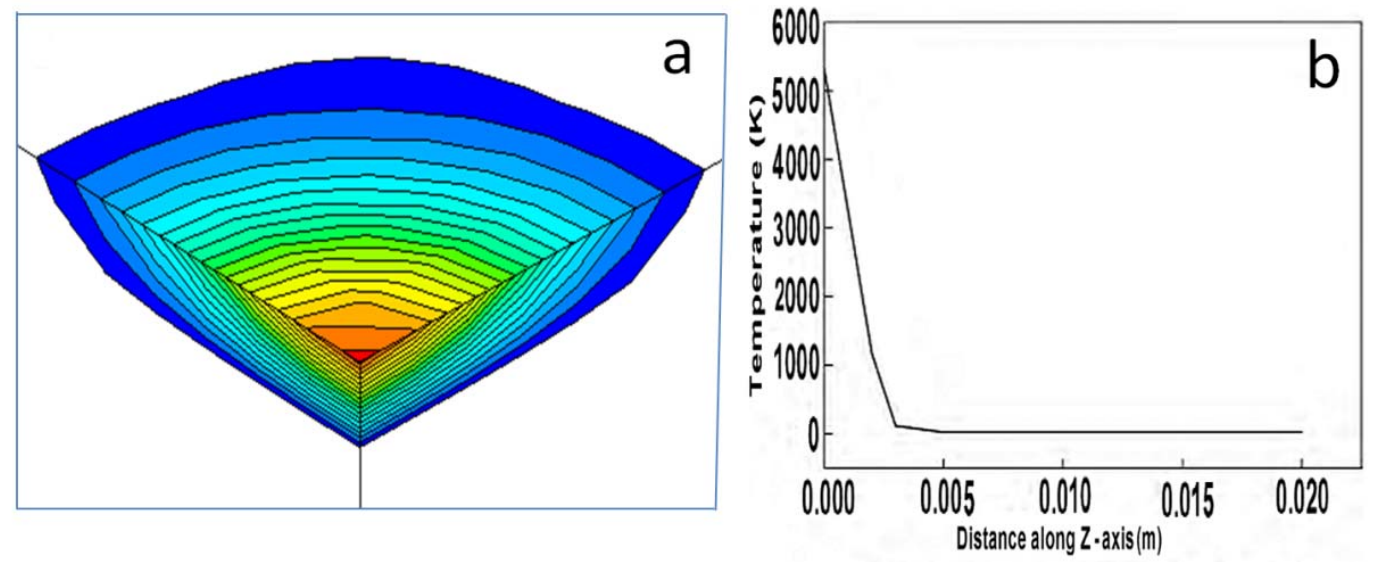

Fig. 2 Temperature field of single pulse discharge: (a)cr12mov as workpiece; (b) temperature curve of cr12mov with depth at the beginning of discharge.
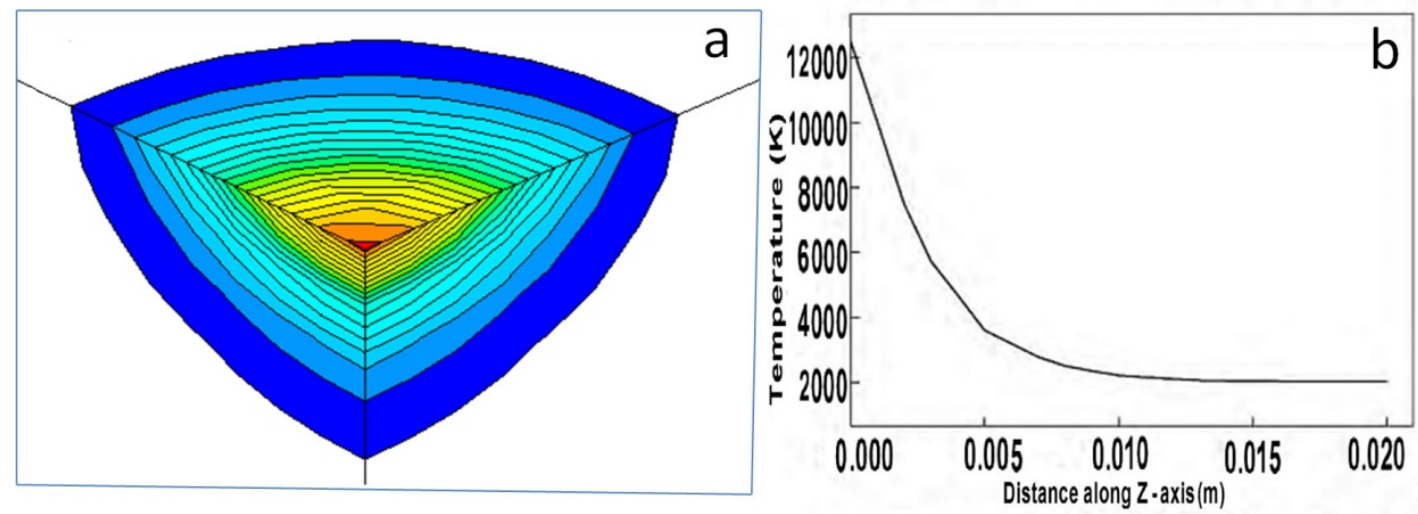

Fig. 3 Temperature field of single pulse discharge: (a)YG8 as deposition material; (b) temperature curve of YG8 with depth at the beginning of discharge. 


\subsection{Effects of Simulation Parameters.}

Fig. 4 is the temperature zone profile by setting inhomogeneous temperature iso-surface. The liquid zone is the melting region, and liquid-solid zone is the semi melting region. Under different curents and durations, once the temperature distribution was obtained, the bestest simulation parameters could be determined [8].
Fig.4(a), Fig.4(b) and Fig.4(c) illustrate the changes of melting region with the change of curents. Compared with this three pictures, we found that melting region becomes lager and lager with currents increasing. In the same way, duration has the same effect as currents, which are shown in Fig.4(d),Fig.4(e) and Fig.4(f).
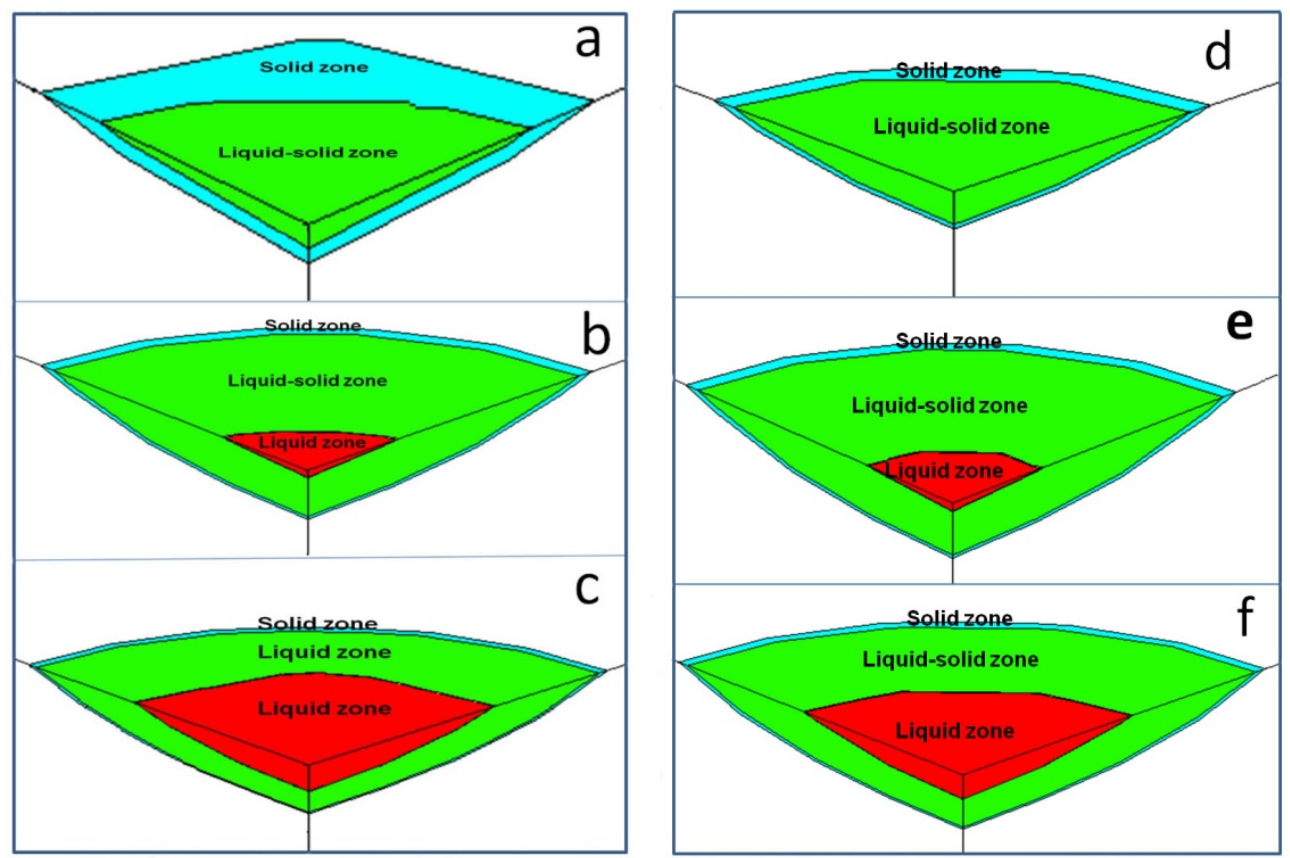

Fig. 4 Effect of discharge current and duration on cr12mov surface:(a) Current=5A; (b) Current=10A;(c) Current=15A; (d) Pulse duration $=20 \mu \mathrm{s}$; (e) Pulse duration $=40 \mu \mathrm{s}$; (f) Pulse duration $=60 \mu \mathrm{s}$

Accordingly, if the discharge current and discharge duration were too small as shown in Fig.4(a) and Fig.4(d), power of electro spark cannot make matrix material reached liquid temperature, therefore, deposition cannot produce. In the same time, if the discharge current and duration were too large as shown in Fig.4(c) and Fig.4(f), power of electro spark make the liquid metal splash out pit.

\section{SUMMARY}

In this study, The electro spark deposition (ESD) was investigated by finite element method with software ANSYS. Temperature distribution was obtained by the finite element model. The deposition liquid zone was calculated based on the simulated result. The parametric study was conducted to find the effects of input parameters on the temperature distribution and contribution of ESD. The following conclusions are drawn from the present study

1. A suitable discharge conditions for ESD deposition process were predicted from the temperature analysis.
2. the contribution of ESD in material deposition increases with increase in energy partition, discharge current and discharge duration.

3 . the optimum parameters were obtained by simulation: the discharge current:10A, the discharge duration: $40 \mu \mathrm{s}$. And the heat effect depth of $\mathrm{cr} 12 \mathrm{mov}$ was $0-0.002 \mathrm{~m}$.

\section{REFERENCES}

[1] G.L. Sheldon, R.Wang, and R.A. Clark, Surf. Coat, Technol., Vol 36(No.1-2), 1988, p445-454.

[2] K.R.C. Somaraju, N.H. Faisal, D.S. Rao, S.V. Joshi, and G. Sundararajan, Electro-spark .Coatings for Enhanced Performance of Twist Drills, Surf. Coat. Technol, 2008, 202, p $1636-1644$

[3] Z.W. Li, W. Gao, M. Yoshihara, and Y.D. He, Improving Oxidation Resistance of Ti3Al and TiAl Intermetallic Compounds with Electro-spark Deposit Coatings, Mater. Sci. Eng. A, 2003, 337, p 243-252.

[4] Shankar P, Jain VK, Sundararajan T (1997) Analysis of spark profiles during EDM process. Mach Sci Tech 1(2):195-217.

[5] Ahn Young-Cheol, Chung YS (2012) Numerical analysis of the electro discharge machining process for alumina tita- 
nium car-bide composite II. Unsteady state approach. Korean J Chem Eng19 (4):694-702.

[6] Carslaw HS, Jaeger JC (1986) Conduction of heat in solids, 2ndedn. Clarendon, Oxford

[7] Eubank PT, Patel MR, BarrufetMA, Bozkurt B (1993) Theoretical models of the electrical discharge machining process III. The vari-able mass, cylindrical plasma model. J Appl Phys 73(11):7900-7909.

[8] Perez R. Rojas H, Walder G (2004), hteroretical modeling of energy balance in electro erosion. J Mater Process Tech149 (1-3):198-203. 